\title{
Features of emotional burnout of pedagogical workers of state and commercial preschool educational organizations
}

\author{
M.V. Naumenko ${ }^{1 *}$, S.V. Zholudeva ${ }^{2}$, and I.N. Ulybysheva ${ }^{3}$ \\ ${ }^{1}$ Academy of Psychology and Pedagogy Southern Federal University, Rostov-on-Don, Russia \\ ${ }^{2}$ Academy of Psychology and Pedagogy Southern Federal University, Rostov-on-Don, Russia \\ ${ }^{3}$ Academy of Psychology and Pedagogy Southern Federal University, Rostov-on-Don, Russia
}

\begin{abstract}
This article addresses phenomenon of emotional burnout. Analyzing the origin of this term, the main approaches to analysis of emotional burnout specificity are described including different symptoms and phases. The problem of value of emotional burnout syndrome of pedagogical workers of state and commercial preschool educational organizations of different types is determined. The results of the research on identification of emotional burnout of pedagogical workers of state and commercial preschool educational organizations specificity, are described. The research is implemented on the sample of survey respondents up to 50 persons using such methods as a questionnaire "Professional (emotional) burnout" (MBI) (K. Maslatch and S. Jackson in adaptation of N.E. Vodopyanova); "Diagnostics of personal emotional burnout" (V.V. Boyko). The conclusions according the existence of distinctions in stages and symptoms of emotional burnout syndrome of pedagogical workers of preschool educational organizations of different types and the importance of the research specificity in appearance of this phenomenon are formulated in order to find the most appropriate preventive and control measures in the sphere of emotional burnout.
\end{abstract}

\section{A problem statement}

An effective professional activity is possible only in case a specialist, who provides it, is in a normative psychological, emotional and physical condition and has sustained professional motivation in addition [1,2]. However, a lot of pedagogical workers suffer from various types of professional deformation leading to decreased performance whereby some researchers consider negative changes, taking place in the structure of personality under professional influence and being called a professional deformation, to be inevitable consequences of a continuous integration in the sphere of professional activity. We can point out a common type of professional deformation for all the specialists, included in a definite type of professional activity, for example, stereotyped perception of an activity object (according to professional identities). Such deformations are considered to be

${ }^{*}$ Corresponding author: ipcs-profped@yandex.ru 
general professional. Besides, individualized types can be pointed out, differentiated among representatives of one and the same professional sphere of activity, who have some personal qualities previously demanded, and having become aggravated with the passage of time [3].

One of the most common and dangerous types of deformation is an emotional burnout [4]. For the first time this phenomenon was introduced by an American Psychiatrist H.J. Fradenberg in 1974. He used this term, examining his colleagues' indirect professional state [5]. Later on researches, devoted to emotional burnout syndrome, became wide spread because of being highly topical.

Thus in $1981 \mathrm{~K}$. Maslatch and S. Jackson, studying the manifestation of emotional burn out syndrome, mentioned that this phenomenon is more typical for representatives of communicative professions [6]. D.V. Dierendonck, W.Schaufeli and H.J. Sixma pointed out a two-dimensional model of an emotional burnout syndrome, including the symptoms of emotional exhaustion and depersonalization [7]. A. Pines and E. Aranson concluded that there is one-dimensional model in emotional burnout, pointed out emotional exhaustion as the main component [8]. V.V. Boyko mentioned cooperation of this syndrome with the state of stress, fixing tension, resistance and exhaustion phases [9].

At present most researchers come to an agreement that:

1) Emotional burnout should be considered as a dynamical phenomenon, revealing in the process of emotional exhaustion, resulting in physical impairments.

2) Emotional burnout is typical for workers of the sphere of persons 'cooperation, tough there is always a risk of its development in any profession.

3) Emotional burnout is a syndrome consisting of mutually supportive symptoms and being diagnosed by their action. Some symptoms, formed in three blocks, are pointed out in the structure of an emotional burnout syndrome:

- Psychophysiological symptoms: enduring tiredness, astenization, weight changes, changes of sleeping and waking regimes, headaches, impairments in stomach and intestinal tract system;

- Social psychological symptoms: an increased level of anxiety, negative emotions (guilt, resentment, shame, insecurity), an increased level of irritability, the absence of positive way of thinking, motivation prevalence to avoid failures;

- Behavior symptoms: substance abuse, prevarication, shifting the responsibility onto others, regime changes, formal relationship to the professional functions, social contacts reduction because of energy economy $[10,11,12]$.

Pedagogical workers as representatives of social professions are among specialists in a group of risk of emotional burnout. In the process of professionalization, the probability that emotional burnout syndrome could start to develop increases with an employment record $[13,14]$. At present specificity of teachers' emotional burnout has been analyzed [15], the differences in emotional burnout between teachers of basic and supplementary education are fixed [16], though peculiarities of emotional burnout of pedagogical workers of preschool education organizations haven't been studied properly yet. Nevertheless, the development of emotional burnout is a rather complicated process, as a person, suffering from this syndrome, cannot realized this fact for a long time and blame the changes of personality structure and professional activity on tiredness and negative coincidence of circumstances.

In this connection the emotional burnout research of pedagogical workers of preschool educational organizations (kindergartens) turns out to be topical and relevant. Children of preschool age become the objects of professional activity of such specialists. The first ones are susceptible to educational and socializing influences of adults and often helpless facing their destructions, that may be caused by such factor as suffering from emotional burnout syndrome. 


\subsection{The objective of the work}

In the Russian Federation all preschool educational organizations are subdivided into two types: the organizations of the first type belong to the municipal authorities and are financed by the state. The attendance of such organizations is free of charge, while the organizations of the second type (their amount is much fewer) are private kindergarten, that are paid by parents. Their characteristics are: highly motivated staff, small-sized groups of children, competitive salary of employees [17], less regulated daily regime and an individual approach to every child.

The purpose of the study is identification of emotional burnout peculiarities of pedagogical workers of state and commercial preschool educational organizations.

The sample of the study consisted of 29 pedagogical workers of the state kindergartens and 21 pedagogical workers of the commercial ones. The total sample turned out to be 50 employees from preschool educational organizations of Rostov-on-Don.

The research didn't tend to find out respondents' emotional burnout depending on the work experience, but in order to exclude the opportunity of such factor's influence on data, the counting of the average work experience of commercial and state organizations staff was done. As a result, it was found that the average pedagogical working experience in the state organizations is about 13 years, while in commercial ones is about 12 years. Such data show that the average work experience of both organizations are approximately on the same level, a little bit more than 10 years' period. This factor gives a reason to state that work experience influences both groups equally, if that matters at all.

In order to get empirical data following methods were used:

- a questionnaire "Professional (emotional) burnout" (MBI) (K. Maslatch and S. Jackson in adaptation of N.E. Vodopyanova). This method was aimed to find out the symptoms of emotional burnout and consisted of twenty-two statements demarcated by three scales equal to burnout symptoms $[18,19]$.

"Diagnostics of personal emotional burnout" (V.V. Boyko). this method was aimed to find out the degrees of intensity and formation of emotional burnout phases; it consisted of eighty-four statements demarcated by twelve scales, each phase included four scales of the method in processing [20].

\section{Materials and the results of the research}

The results derived from the questionnaire "Professional (emotional) burnout" (MBI) (K. Maslatch and S. Jackson) are presented in figure 1.

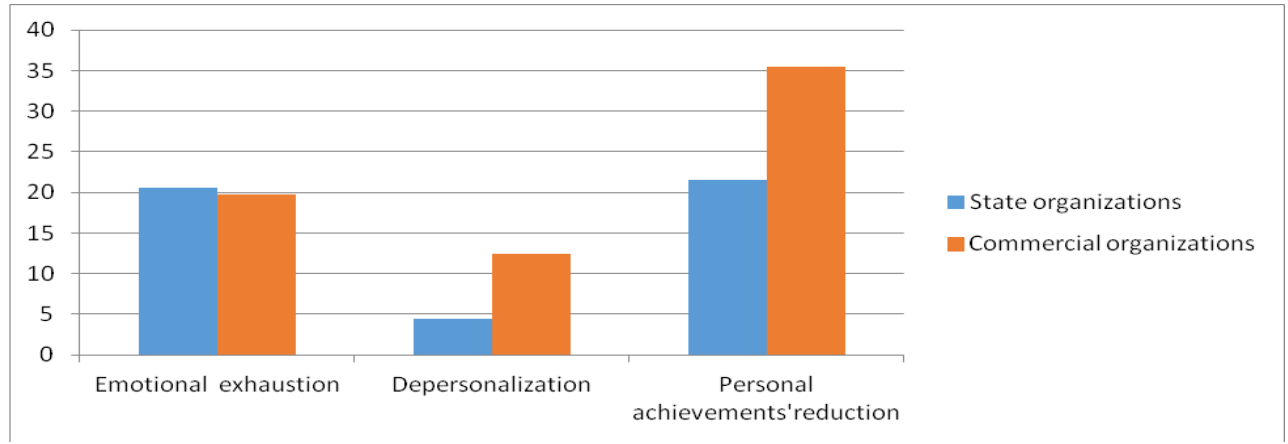

Fig. 1. Diagnostics of emotional burnout syndrome of pedagogical workers of state and commercial preschool educational organizations. 
According to the scale "Emotional exhaustion" the level of emotional exhaustion is almost equal in both groups, the difference between them is no more than one point. According to the method pedagogical workers of state educational organizations get 20,6 points, while those of commercial organizations get 19,7 points, that is equal to the average degree of intense. In the scale "Depersonalization" that is also one of the symptoms of emotional burnout, pedagogical workers of state educational organizations have 4,5 points, that reflects a low level of the method. At the same time pedagogical workers of commercial educational organizations have the average values of 12,4 points, that, according to the scale, reflects a high level of the symptom intensity. The scale "Personal achievements' reduction" is opposite: 35 points in a group of commercial organizations reflect a low degree of intensity of this symptom, while a level of 21,6 points, that is typical for pedagogical workers of state educational organizations, on the contrary, shows a high level of intensity.

The differences in the symptoms of emotional burnout (according to the scales) between pedagogical workers of state educational organizations and those of commercial ones are confirmed by the statistical analysis, carried out with the help of Mann-Whitney U-test.

Table 1. The results of the statistical analysis of emotional burnout symptoms with the help of Mann-Whitney U-test.

\begin{tabular}{|l|l|l|}
\hline Scales & U & P \\
\hline Emotional exhaustion & 263,000 & $\mathrm{p}>0.05(380)$ \\
\hline Depersonalization & 69,000 & $\mathrm{p} \leq 0.01(, 000)$ \\
\hline Personal achievements' reduction & 42,000 & $\mathrm{p} \leq 0.01(, 000)$ \\
\hline
\end{tabular}

According to the table it is clearly seen that there are considerable discrepancies between the samples of pedagogical workers $U=69, U=42$ when $p \leq 0.01$ in the scales of "Depersonalization" and "Personal achievements' reduction", while the scale "Emotional exhaustion" does not reflect such discrepancies.

The results derived with the help of the method "Diagnostics of personal emotional burnout" (V.V. Boyko) are represented in figure 2.

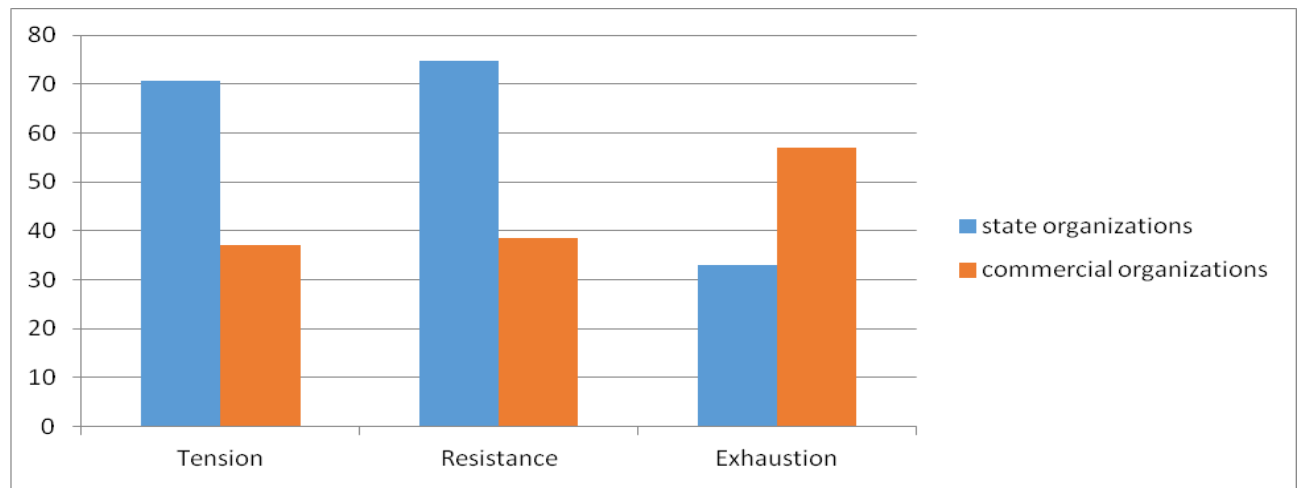

Fig. 2. Diagnostics of phases of emotional burnout of pedagogical workers of state and commercial preschool educational organizations.

The phase "Tension" is given as a primary phase of emotional burnout and is more expressed within the group of pedagogical workers of state organizations. The average results of this group respondents make up 70,6 points according to the method, that shows a formed phase, while pedagogical workers of commercial organizations have an average point of 37,1, that reflects an average level of intensity. 
Almost similar data were derived in the phase "Resistance": 74,8 points - in the group of state educational organization and 38,6 - in the group of commercial preschool organizations.

The phase "Exhaustion" is of great interest as it is more expressed within pedagogical workers included in the system of commercial preschool education - 57,1 points that reflects an average level of intensity, while their colleagues from the state educational organizations do not have this phase formed that is reflected in the average point of 33,1 .

The discrepancies in emotional burnout level derived between pedagogical workers of state and commercial preschool educational organizations are proved by the statistical analysis carried out with the help of Mann-Whitney U-test.

Table 2. The results of the statistical analysis of emotional burnout levels with the help of MannWhitney U-test.

\begin{tabular}{|l|l|l|}
\hline Scales & $\mathbf{U}$ & $\mathbf{P}$ \\
\hline Tension & 78,500 & $\mathrm{p} \leq 0.01(, 000)$ \\
\hline Resistance & 72,500 & $\mathrm{p} \leq 0.01(, 000)$ \\
\hline Exhaustion & 125,000 & $\mathrm{p} \leq 0.01(, 000)$ \\
\hline
\end{tabular}

According to the table it is clearly seen that there are considerable discrepancies between the samples of pedagogical workers in the scales on the level $p \leq 0.01$.

The data derived from the study of the symptoms of emotional burnout (a questionnaire K. Maslatch and S. Jackson), lead to following suggestions:

Taking into account that the results of both groups equal to the average level of the symptom "emotional burnout" development that indicates a reduced emotional background of the respondents and appearance of some difficulties in emotional control, pedagogical workers are suggested to use an emotional detachment in order to have psychological defense or suffer from lack of emotions. Whereas data of development are typical for both groups.

According to derived results in the scale of "Depersonalization" it is a group of commercial organizations that possesses such qualities as overdependence on surrounding, significance of external evaluations, that is explained by high requirements formulated by authorities of such organizations. However, at the same time a high level of this symptom reflects cynical attitudes and feelings towards the subjects of the professional activity. In this case cynics can be seen in the relationships with children and their parents.

The scale "Personal achievements' reduction" turns out to be opposite: the higher indicators in this scale, the less symptom is developed. Thus, the group of workers of the state educational preschool organizations is characterized by lower self-assessments, the reduction of own professional achievement, negative attitudes towards professional abilities. Moreover, such pedagogical workers are inclined to reduce their professional duties towards the objects of professional activity.

The study of emotional burnout phases (a method of V.V. Boyko) leads to following suggestions:

The resistance phase is more typical in the development of burnout syndrome for pedagogical workers of the state preschool educational organizations, it means that respondents of this group actively oppose burnout symptoms and try to cope with factors initiating it. While the exhaustion phase dominates in the group of commercial organizations. This result can be explained by the fact that such workers, being highly dependent on external evaluation, common cynics with aspiration to achieve higher results, lack internal energy sources to fight the syndrome of burnout. Therefore, the process of emotional burnout is typical for representatives of both groups, but at the same time each group possesses its own intense phase of emotional burnout. 
In this connection peculiarities of work experience in the sample are worth being mentioned as previous researches confirm the dependence of emotional burnout development on the work experience. An average work experience in the group of commercial organizations is 13 years, while in the group of state organizations is 12 . Thus, the discrepancies in work experience between the samples are minor, and at the same time the last phase of exhaustion is a characteristic feature of the group of commercial organizations, that indicates accelerated development of burnout between pedagogical workers of preschool commercial organizations.

\section{Conclusions}

The problem of emotional burnout of pedagogical workers of preschool educational organizations is rather relevant and requires thorough analysis and study in order to reduce a risk of development and prevention of a burnout syndrome. It is necessary to possess information regarding burnout peculiarities typical to workers of preschool organizations of any type in order to affectively work solving this problem. As a result of the research the symptoms of emotional burnout of pedagogical workers of preschool state and commercial organizations were registered. Considerable discrepancies between studied groups in a degree of symptoms development: depersonalization and personal achievements' reduction were found out. The emotional burnout phases of workers of state and commercial preschool organizations were stated. In all studied scales such as "tension", "exhaustion", "resistance" considerable discrepancies between studied groups of respondents were defined.

The derived data give an opportunity to:

- define distinctive features (symptoms and dominating phases) of emotional burnout of workers of both types of studied organizations;

- analyze all possible reasons, launching the process of development of burnout syndrome of pedagogical workers of state and commercial preschool educational organizations;

- find the most effective way to deal with pedagogical workers of every studied group with the aim of preventing and overcoming this syndrome based on the information received.

\section{References}

1. E.P. Ilyin, Motivation and motives, p. 512 (Saint Petersburg: Piter, 2000)

2. V.A. Shahova, S.A. Shapiro, Motivation of labour action, p. 134 (Moscow: Alfa-Press, 2006)

3. S.A. Druzhilov, Professional deformation and destructions: phenomenology and approaches to research, International Journal of Applied and Fundamental Research, 11, 37-40 (2013)

4. E.E. Symannuk, E.F. Zeer, Psychology of professional destructions, p. 240 (Moscow: Academic project, 2005)

5. Freundenberger, H.J. Staff burn out, Journal of social sciences, 30, 159-166 (1974)

6. K. Maslach, Burnout: multivariate prospect, p. 150 (Moscow: Institute of Psychotherapy Publ., 2009)

7. D.V. Dierendonck, W.B. Schaufeli, H.J. Sixma, Burnout among general practitioners: a perspective from equity theory, Journal of Social and Clinical Psychology, 13 (1), 86100 (1994) 
8. A.M. Pines, E. Aronson, Career burnout. Causes and cures, p. 229 (N.Y.: The Free Press, 1988)

9. V.V. Boyko, Energy of Emotions in Communication: View of oneself and of others, p. 472 (Moscow: Filin, 1996)

10. N.A. Aminov D.V. Shpitalniy, The syndrome of "emotional burnout" as a type of professional disadoptation, Professional potential, 1, 45-48 (2002)

11. L.E. Larentsova, Phenomenon of emotional burning out: the formation mechanism, symptoms and ways of overcoming from the point of view of various psychological approaches, Legal psychology, 2, 37-48 (2009

12. V.E. Orel, The phenomenon of influence in foreign psychology, Psychological Journal, 1, 34-42 (2001

13. V.V. Lukyanov, I. E. Sorokoletova, Burnout and professionalization, p. 440 (Kursk: Kursk State University, 2013)

14. A.N. Vasykova, N.V Klimenko, Emotional burnout syndrome in professional activity of a teacher, Psychology and Pedagogics: methods and problems of practical usage, 18, 147-151 (2011

15. M.V. Naumenko, S.V. Joludeva, Emotional burnout of teachers with different way of behavior in conflict, Scientific notes of University named P.F. Lesgaft, 1 (143), 261265 (2017)

16. M.V. Naumenko, A.U. Tutunnikova, Peculiarities of interaction of professional submissions and professional burnout of teachers of additional education, Professional submissions, 1 (11), 178-183 (2019)

17. M.V. Naumenko, E.E. Rogova, E.I. Rogov, Peculiarities of professional motivation of private and public schools teachers, p. 135-142 (Belgrade: Center for Open Access in Science, 2019)

18. N.E. Vodopyanova, Syndrome of "psychological burnout" in communicative professions, p. 504 (Saint Petersburg: Piter, 2000)

19. N.E. Vodopyanova, E.S. Starchenkova, Burnout syndrome: diagnostics and prevention, p. 258 (Saint Petersburg: Piter, 2008)

20. V.V. Boyko, Syndrome of emotional burnout in professional communication, p. 105 (Saint Petersburg: Piter, 1999) 